\title{
La congélation et le stockage du fromage de chèvre(1)
}

\author{
par \\ A. PORTMANN \\ Laboratoire Technologie Laitière - I.N.R.A.
}

\section{La conservation du lait...}

Le problème se pose de répartir la production de lait de chèvre sur toute l'année. La solution consiste à conserver le lait récolté pendant la période de lactation maximum pour le réutiliser au moment où la production est la plus faible, c'est-à-dire de novembre à mars.

Le lait peut être stocké sous forme de poudre ; celle-ci, après avoir été additionnée d'eau pour parvenir au volume initial du lait, est ajoutée au lait frais lors de la fabrication du fromage de chèvre. Cependant, l'apport de lait "reconstitué » ne doit pas dépassé 15 p. 100 de la quantité de lait frais. L'incorporation de poudre de lait de chèvre en quantité plus grande exerce une influence défavorable sur la qualité des fromages.

La conservation du lait à l'état de fromage permet de parvenir à des résultats plus satisfaisants. Toutefois, une température égale ou inférieure à $-18^{\circ} \mathrm{C}$. L'application de ce procédé au fromage affiné ne donne pas, en général, entière satisfaction et il est donc souhaitable de conserver le fromage avant affinage. L'affinage est effectué ultérieurement, sur le fromage décongelé.

\section{...Et du caillé égoutté et congelé}

De nombreuses laiteries utilisent le report du lait de chèvre á l'état de caillé égoutté et congelé. L'égouttage peut être effectué soit en sac, soit dans un filtre à caillé "Bergé ". Dans deux tanks de 80001 le lait est emprésuré et additionné de levain puis maintenu à $21^{\circ} \mathrm{C}-1^{\circ} \mathrm{C}$ pendant 20 à $24 \mathrm{~h}$. Le caillé est ensuite envoyé dans les toiles du filtre à caillé. Après l'égouttage qui se poursuit pendant 12 à $15 \mathrm{~h}$ de manière à parvenir à une teneur en matière sèche de 39 à 42 p. 100, le caillé est réparti en blocs de $25 \mathrm{~kg}$ enveloppés

(1) La Revue de l'Elevage, 1969, numéro spécial : moutons et chèvres. 
TABLEAU I

Examen organoleptique de fromages préparés avec du caillé congelé et stocké à $-20^{\circ} \mathrm{C}$

\begin{tabular}{|c|c|c|c|c|}
\hline \multirow{2}{*}{$\begin{array}{c}\text { Lot de } \\
\text { lait }\end{array}$} & \multirow{2}{*}{$\begin{array}{l}\text { Fromages préparés avec } \\
\text { le caillé frais témoin }\end{array}$} & \multicolumn{3}{|c|}{$\begin{array}{l}\text { Fromages préparés avec le caillé maintenu à }-20^{\circ} \mathrm{C} \\
\text { pendant une durée de conservation de : }\end{array}$} \\
\hline & & 2 mois & 5 mois & 9 mois \\
\hline$I \ldots \ldots c c c c$ & très bon, onctueux & bon, onctueux & légèrement oxydé & Oxydé, goût de suif \\
\hline II $\ldots \ldots \ldots$ & bon & assez bon & assez bon & assez bon \\
\hline
\end{tabular}

TABLEAU II

Degré d'oxydation du fromage préparé avec du caillé stocké pendant 5 et 9 mois à $-20^{\circ} \mathrm{C}$.

Le degré d'oxydation a été apprécié par le test à l'acide thiobarbiturique et par examen organoleptique

\begin{tabular}{|c|c|c|c|c|c|}
\hline \multirow{3}{*}{$\begin{array}{l}\text { Lot de } \\
\text { lait }\end{array}$} & \multirow{3}{*}{$\begin{array}{c}\text { Test d'appréciation de } \\
\text { l'oxydation }\end{array}$} & \multicolumn{4}{|c|}{ Durée de conservation du caillé à $-20^{\circ} \mathrm{C}$} \\
\hline & & \multicolumn{2}{|c|}{5 mois } & \multicolumn{2}{|c|}{9 mois } \\
\hline & & $\begin{array}{l}\text { Caillé conservé } \\
\text { sans sel }\end{array}$ & \begin{tabular}{|c|} 
Caillé salé avec \\
1,6 p. 100 de sel avant \\
la conservation
\end{tabular} & $\begin{array}{c}\text { Caillé conservé } \\
\text { sans sel }\end{array}$ & $\begin{array}{l}\text { Caillé salé avec } \\
1,6 \text { p. } 100 \text { de sel avant } \\
\text { la conservation }\end{array}$ \\
\hline I $\ldots \ldots c c c c \mid$ & dégustation & légèrement oxydé & $\begin{array}{l}\text { très oxydé, } \\
\text { goût de suif }\end{array}$ & $\begin{array}{l}\text { très oxydé, } \\
\text { goût de suif }\end{array}$ & $\begin{array}{l}\text { goût de suif } \\
\text { très prononcé }\end{array}$ \\
\hline & valeur T.B.A. & 0,076 & 0,409 & 0,179 & 1,030 \\
\hline II $\ldots \ldots c c c c$ & $\begin{array}{l}\text { dégustation } \\
\text { valeur T.B.A. }\end{array}$ & $\begin{array}{l}\text { assez bon } \\
\text { aucun défaut } \\
0,024\end{array}$ & $\begin{array}{c}\text { assez bon } \\
\text { aucun défaut } \\
0,024\end{array}$ & $\begin{array}{c}\text { assez bon } \\
\text { aucun défaut } \\
0,028\end{array}$ & $\begin{array}{c}\text { assez bon } \\
\text { aucun défaut } \\
0,044\end{array}$ \\
\hline
\end{tabular}


dans des feuilles d'aluminium ou de matière plastique puis déposés dans des caisses en carton ; le caillé est alors conservé pendant 4 à 6 mois entre $-15^{\circ} \mathrm{C}$ et $-20^{\circ} \mathrm{C}$ selon les installations. A la fin du stockage, le caillé est décongelé puis moulé soit à l'aide d'une mouleuse à vis, soit en tassant le caillé avec une spatule dans un moule contenant un morceau de mousseline.

La conservation du caillé à $-18^{\circ} \mathrm{C},-20^{\circ} \mathrm{C}$ pendant plusieurs mois donne en général satisfaction. Cependant, comme nous l'avons montré précédemment (Portmann et al., 1966, 1967, 1968), il arrive que les fromages préparés avec certains lots de caillé stocké présentent des mauvais goûts. Ceux-ci sont de deux types ; ce sont soit des goûts d'oxydé, soit des goûts plats douceâtres.

\section{Les goûts d'oxydé, goût de suif, goût de poisson ou goût métallique}

Ils résultent d'un phénomène physico-chimique, l'oxydation des acides gras. Alors que certains lots de caillé peuvent être conservés pendant 6 à 7 mois sans que les fromages présentent de mauvais goûts, d'autres ont un goût de suif après 5 mois de conservation, comme on peut le voir sur le tableau I.

Dans le tableau II, on a reporté le degré d'oxydation apprécié d'une part par des examens organoleptiques et, d'autre part, à l'aide du test à l'acide thiobarbiturique. On voit que l'addition de sel au caillé avant la conservation provoque, au cours du stockage à basse température, une augmentation du goût d'oxydé,. Le procédé de salage, qui consiste à incorporer à la masse du caillé 1,6 p. 100 de sel à l'aide d'un léger malaxage, doit toujours être effectué après la conservation, au moulage.

Pour tenter de limiter les accidents relatifs à l'oxydation de la matière grasse du fromage, nous étudions quels sont les facteurs qui en sont responsables et cherchons à mettre au point un test rapide pour juger de la qualité de conservation du caillé dès sa fabrication.

\section{Les goûts plats et les goûts douceâtres}

Ils résultent d'un phénomène biochimique, la dégradation enzymatique des protéines et de la matière grasse. Ces enzymes sont produites par les micro-organismes de contamination et leur action est plus sensible dans les fromages préparés avec du caillé conservé à basse température qu'avec du caillé frais. Il faut remarquer qu'il est plus facile d'éviter ces défauts de goût que l'oxydation car ils sont liés à la contamination excessive du lait. Les soins d'hygiène à la récolte sont simples à appliquer et les producteurs de lait devraient faire un important effort dans ce sens car, comme nous avons pu le voir au cours de nos travaux, il est assez fréquent de trouver du lait de chèvre contenant de 50 à 100 millions de bactéries par $\mathrm{ml}$, et plus de 100000 bactéries coliformes par $\mathrm{ml}$, ce type de bactéries traduisant assez bien le manque de soins d'hygiène à la 
récolte du lait. Or, on sait que de la qualité bactériologique du lait dépend la qualité des fromages.

Nous avons vu que la congélation et la conservation du lait de chèvre s'effectuait à l'état de caillé égoutté et congelé et que le moulage des fromages était fait après la décongélation. La structure de ces fromages, légèrement granuleuse et collante, est différente de celle des fromages préparés selon le processus traditionnel où l'égouttage et le moulage s'effectuent simultanément.

La congélation et la conservation à basse température des fromages " traditionnels » non affinés devrait permettre de conserver la structure de pâte à laquelle les consommateurs de fromage de chèvre sont habitués. Cependant, il semble que la congélation puis la décongélation dégradent légèrement la structure de ces fromages et des études doivent être poursuivies pour fixer les conditions optimum de traitement.

\section{En conclusion}

La solution qui consiste à utiliser une basse température semble actuellement, malgré les difficultés évoquées plus haut, le moyen le plus satisfaisant dont nous disposions à l'heure actuelle pour effectuer le report du lait de chèvre en dehors de la période de lactation maximum. La conservation du caillé égoutté et, éventuellement, du fromage non affiné est un procédé valable. La congélation doit être effectuée le plus rapidement possible après la fabrication et la température de la chambre frigorifique située à $-18^{\circ} \mathrm{C}$ au maximum, ne doit pas subir de fluctuations importantes pendant toute la durée de conservation.

Il est possible que l'utilisation d'une température plus basse soit souhaitable et nous poursuivons des recherches à $-40^{\circ} \mathrm{C}$.

Enfin, l'utilisation de lait de bonne qualité bactériologique doit permettre de limiter les défauts de goûts et fournir aux consommateurs des produits de qualité satisfaisante. 